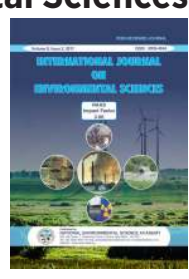

\title{
EFFECTS OF PESTICIDES ON BIODIVERSITY AND CLIMATE CHANGE
}

\author{
Vinod K. Chaudhary ${ }^{1}$, Sunita Arya ${ }^{2^{*}}$ and Prabhakar Singh ${ }^{3}$ \\ ${ }^{1}$ Department of Environmental Science, Dr. RML Avadh University, Ayodhya (U.P.) \\ ${ }^{2}$ Department of Zoology, DG PG College Kanpur (U.P.) \\ ${ }^{3}$ Department of Anthropology, University of Allahabad, Prayagraj (U.P.)
}

Review Article

Received: 30.10.2021

Accepted: 11.11.2021

Published: 20.11.2021

\begin{abstract}
Pesticides are the biological pollutants, which are being used by the man to kill the pests for increasing the yield of many crops and insect vectors to control the spread of disease. The tremendous use of pesticides has caused severe health hazards to organisms including human beings due to climate change. Excessive use of pesticides may lead to the destruction of biodiversity. Many birds, aquatic organisms and animals are under the threat of harmful pesticides for their survival. The pesticides effects can be lessen by organizing awareness program among the farmers, special training to them regarding consequences of pesticides, their screening and monitoring methods.
\end{abstract}

Keywords: Pesticides, Biodiversity, Environmental hazards, Climate change.

\section{INTRODUCTION}

Pesticides are biological toxicant that are deliberately released into the environment in order to kill, prevent, deters, control, destroy, repel or mitigate population of insect, weeds, rodents, fungi, or other harmful pest in agricultural, domestic and industrial setting. In agricultural field the use of pesticide has become a common practice to increase the crop yield through controlling pest and insect vectors to control the spread of pest related diseases (Prakash and Verma, 2014). Pesticides are being used extensively in the control of crop pests, mosquito and vector borne diseases; hence, the production of pesticides has greatly increased in recent years. Pesticides include a wide variety of chemicals with great difference in their mode of action, uptake by the body, metabolism and elimination from the body and toxicity to target and nontarget organism. The main groups of commonly used pesticides are insecticides, fungicides, fumigants, and rodenticides.

The use of pesticides increased many fold over the past few decade. It is estimated that about 5.2 billion pound of pesticides are used worldwide annually (Dutta and Bortamuly, 2018). Majority of pesticide are not particularly targeting the pest. The widespread use of pesticides not only brought adverse influence on agro ecosystems but also caused alteration in physiological processes of non-target organisms (Verma and Prakash, 2018). It has been assessed that only about $0.1 \%$ pesticide stretch out the target entity and remaining are taint with the surrounding environment (Dutta and Bortamuly, 2018). Poisoning risks depend on dose, toxicity, duration of exposure and sensitivity (Prakash, 2020).

These pesticides through surface runoff reach into the aquatic ecosystems and become a global environmental problem. The presence of pesticides in the aquatic system can obviously lead to multi- fold interaction with other forms of pollution because these pesticides enter into the food chain and their subsequent bioaccumulation and biotransformation at different trophic levels have catastrophic effect to the ecosystem (Prakash and Verma, 2014; Sandeep, 2021).

*Corresponding author: greenindia2@gmail.com 
The over and misuse of pesticide has precedence to immense health problem, economic loss and various environmental problem. The resultant health problem of pesticide includes cancer, birth defect, reproductive problem, liver, kidney, and neural problem etc. In many developing countries majority of pesticide are associated with adverse effect on human health and environment due to the in judicial use of pesticide. On the other hand the overused of pesticide also precedence to the environmental pollution such as water, soil pollution etc. and cause imbalance of ecosystem. The ecological balance is needed for widespread biodiversity and human survival (Verma. 2017; Ashok, 2018).

Synthetic pesticides are widely used in India to increase the production of crops. It is also used in public health application to control insects such as cockroaches, mosquitoes, ticks, and flies which may act as a disease vector (Kaur and Mishra, 2020), however hybrid pesticide is more eco-friendly (Tripathi, 2021).The synthetic pesticides are of mainly two types Organochlorine and organophosphorus. However, variety of pesticides like organochlorines, organophosphates, carbamates and synthetic pyrethroids are easily available in market and now in use (Shinde, 2021; Masih, 2021). The main aim of present discussion is to look out the effects of pesticides on public health, biodiversity and climate change.

\section{Pesticide and Environment}

Mostly farmers and field workers are either illiterate or less educated and hence they applied pesticides without screening and proper specific information, due to which various hazardous effect posed on environment. Multitudinous use of pesticide without screening on daily basis also affects the non-target organisms. Due to irregular screening sometimes they used pesticide abundantly after damaging the crop. Ultimately those are persisting for long time in the environment and causes environmental pollution specially soil pollution. The innumerous use of pesticides also kills the helpful microorganism as a result of which the self-fertility property of soil is reduced. Regarding pesticides it is important to have practical understanding of their physical and chemical properties, since their solubility determine the transportation of surface runoff and absorbing capacity of soil (Bernardes et al., 2015).
In environment the pesticides are tempo rated long distance and their deposition to water causes water pollution. In several cases pest are resistances to a particular pesticide as effect of natural selection, which cause hazards to non-target organisms and cause sudden death of that organism. On the contrary, the pesticides which are demoted through photo decomposition, microorganisms, or through physical or chemical reaction. But the un-demoted pesticides are remaining on environment over long time which greatly causes environmental damage. The long time persisting pesticide causes hazards to biodiversity of aquatic or terrestrial organisms. Pesticides are entered to aquatic ecosystem that act as toxic agent and causes hazard to aquatic plants and animals.

\section{What is Climate Change?}

Climate change is also a day to day phenomenon but it should best be referred as climate variability or environmental change. Climate change is the change of climate over a longer period of time ranging from decades to centuries caused both by natural and human induced changes. According to UNFCCC (United Nations Framework Convention on Climate Change), climate change is a change of climate which is attributed directly or indirectly to human activity that alters the composition of the global atmosphere and which is in addition to natural climate variability, observed over comparable time periods. Thus, UNFCCC uses the term 'climate change' to mean only those changes that are brought about by human activities.

Huge data collected, collated and compiled by UNFCC and IPCC indicated that the globally average effect since 1750 has been one of warming and by 2100 the average temperature of the world will rise by $1.8^{\circ} \mathrm{C}$ to $4.0^{\circ} \mathrm{C}$. To understand the phenomenon in a simple way, the concentration of certain gases (called as greenhouse gases or GHGs) is increasing considerably due to human activities mainly burning of coal and petroleum. Carbon di-oxide $\left(\mathrm{CO}_{2}\right)$ is the main culprit and other gases are methane, nitrous oxide, sulphur hexa fluoride, hydrofluoro-carbons and per fluorocarbons. These gases trap the heat from sunlight and do not allow it to be reflected back thus the earth is getting gradually warmer. These gases have different warming potential, if carbon dioxide's warming potential is 1 , it is 21 for methane, 310 for nitrous oxide, 23900 for sulphur hexafluoride, 11700 for hydrofluorocarbons and 9200 for perfluorocarbons. 
The result of this warming which is already being felt in many parts of the world shall be heat waves, increased frequency of heavy precipitation, increased frequency of tropical cyclones, water and food scarcity, increased abundance of Malaria, dengue and other diseases, severe loss of biodiversity which will have serious social, economic, political and environmental consequences.

\section{Effect of pesticide on Biodiversity}

Rising temperature of earth surface changes the biological clock of animals especially insects and flowering of plants including weeds (Prakash, 2021; Verma, 2021). Warm atmosphere is suitable for growth and proliferation of both insect pests and weeds, so to control these weeds and pests both developed and developing countries quickly used more pesticides (herbicides and insecticides). The industries are incessantly release a variety of synthetic pesticides into the biosphere.

Pesticide effects on the populations of aquatic and terrestrial plants as well as animals including birds. Accumulation of pesticides in the food chains is of greatest concern as it directly affects the predators and raptors. But, indirectly, pesticides can also reduce the quantity of weeds, shrubs and insects on which higher orders feed. Natural bio control method for weeds is better from environment and biodiversity point of view (Tripathi and Tripathi, 2021). Spraying of insecticides, herbicides and fungicide have also been linked to declines in the population of rare species of animals and birds.

Pesticides enter into the water bodies like ponds and rivers which alters the physicochemical properties of water. It in turn proves toxic to aquatic organisms and pesticide contaminated water poses a great threat to aquatic form of life. It can affect aquatic plants, decrease dissolved oxygen in the water and can cause physiological and behavioural changes in fish populations. About $80 \%$ of the dissolved oxygen is provided by the aquatic plants and it is necessary for the sustenance of aquatic life. Killing of aquatic plants by the herbicides results in drastically low oxygen levels and ultimately leads to suffocation of fish and reduced fish productivity. However, pesticides reach underground through seepage of contaminated surface water, improper disposal and accidental spills and leakages.
Pesticides which are applied to land drift to aquatic ecosystems and there they are toxic to fishes and nontarget organisms. These pesticides are not only toxic themselves but also interact with stressors which include harmful algal blooms. With the overuse of pesticides, a decline in populations of different fish species is observed (Scholz et al., 2012). Pesticides have been found toxic for several amphibian species, whereas, herbicide glyphosate is known to cause high mortality of tadpoles and juvenile frogs (Relyea, 2005). Aquatic animals are exposed to pesticides in three ways: Dermally (Direct absorption via skin), Breathing (Uptake via gills during breathing) and Orally (Entry via drinking contaminated water.

Pesticide exposure can also cause sub-lethal effects on terrestrial organisms in addition to killing non-target organisms. Populations of beneficial insects such as bees and beetles can significantly decline by the use of broad-spectrum insecticides such as carbamates, organophosphates and pyrethroids. Insect population has also been found to be greater on organic farms compared to non-organic ones. Since 2006, each year, honey bee populations have dropped by 29-36 \%. Since pre-agricultural times, 20-25\% of the bird populations have declined. One of the major causes of this massive decline is the use of pesticides which was not known before 1962. Pesticide accumulation in the tissues of bird species leads to their death. Bald eagle populations in the USA declined primarily because of exposure to DDT and its metabolites (Liroff, 2000).

\section{SUMMARY}

Pesticides have proved to be a boon for the farmers as well as people all around the world by increasing crop production and by providing innumerable benefits to society indirectly. On the contrary those cause adverse effect to environment such as pollution and causes imbalance of ecosystem and unsustainable agriculture (Ashok, 2017b). Consequences of overuse of pesticides and unsustainable agriculture including environmental deteriorations should be narrated to farmers so that inclusive and sustainable development with environmental ethics can be achieved (Verma, 2019). Those problems regarding pesticide are occurring due to the improper knowledge, unaware about pesticide types, level of poisoning, lack of daily screening and awareness about their harmful effect on environment and health. But the issue of hazards posed by pesticides to biodiversity and the environment has 
raised concerns about the safety of pesticides. The enormous use of pesticide becomes the predominant environmental contaminants. Once these pesticides are released in the environments they are metabolized in short time where as other persists over longer period and can accumulate in the soil and water and badly influence the widespread biodiversity and its buffering mechanism (Ashok, 2017; Prakash and Verma, 2020).

Although we cannot completely eliminate the hazards associated with pesticide use, but we can circumvent them in one way or the other. Exposure to pesticides and hence the harmful consequences and undesirable effects of this exposure can be minimized by several means such as alternative cropping methods or by using well-maintained spraying equipment or by using pesticides of plant origin.

The bitter experience of the use of synthetic pesticides and presence of rich flora in our country attracts the attention of scientists to develop an effective and economic control method by exploring the bio pesticides (Ansari et al., 2004a). So, it has become necessary to evolve control measures, which may be selective in action and relatively harmless to nontarget organisms and human beings (Ansari et al., 2003). Thus pesticides of plant origin are preferred over synthetic pesticides because of nontoxic to environment and human beings (Ansari et al., 2004b).

\section{REFERENCES}

1. Ansari, K.K., Prakash, S. and Pandey, P.N. (2003). Population control of rice moth Corcyra cephalonica (Stainton) by some indigenous plant products. Flora and Fauna. 9(1):22-24.

2. Ansari, K.K., Prakash, S. and Pandey, P.N. (2004a). Efficacy of some indigenous plant products on the emergence and longevity and percentage of hatching of rice moth Corcyra cephalonica (Stainton). Flora and Fauna. 10(1):35-36.

3. Ansari, K.K., Prakash, S. and Pandey, P.N. (2004b). Effect of some plant products on Oviposition period, fecundity and percentage of hatching of rice moth Corcyra cephalonica (Stainton). Flora and Fauna. 10(2):159-160.

4. Ashok K.V. (2017a). Genetic Diversity as Buffer in Biodiversity. Indian Journal of Biology. 4(1): 61-63.
5. Ashok K.V. (2017b). Multiple effects of Unsustainable Agriculture. International Journal on Agricultural Sciences. 8(1): 24-26.

6. Ashok K.V. (2018). Ecological Balance: An Indispensable Need for Human Survival. Journal of Experimental Zoology, India. 21 (1): 407-409.

7. Benardes, MFF, Panzin, M., Pererei, L.C. and Dorta, D.J. (2015). Impact of pesticides on environment and human health. Journal of Toxicological Study, 195-233. http//dx.doi.org/ 10.5772/59710.

8. Dutta, N. and Bortamuly, M. (2018). Pesticides and its effect on health and environment. International Journal of Research and Analytical Reviews. 5(4): 57-59.

9. Kaur, G. and Mishra, B.K.P. (2019). Histopathological changes in Liver of fish Channa punctatus exposed to sub lethal concentration of Hybrid Pesticide. International Journal of Biological Innovations.1(2):83-86.https:/ /doi.org/10.a46505/IJBI.2019.1209

10. Liroff, R.A. (2000). Balancing risks of DDT and malaria in the global POPs treaty. Pestic Safety News, $4: 3$

11. Masih, S.C. (2021). Impact of Monocrotophos pesticide on serum biochemical profile in freshwater fish, Cirrhinus mrigala (Hamilton, 1822). International Journal of Biological Innovations. 3(2):402-406. https:// doi.org/10.46505/IJBI.2021.3222

12. Prakash, S. (2020). Toxic effect of chlorpyrifos pesticides on the behaviour and serum biochemistry of Heteropneustes fossilis (bloch). International Journal on Agricultural Sciences. $11(1): 22-27$.

13. Prakash, S. (2021). Impact of Climate change on Aquatic Ecosystem and its Biodiversity: An overview. International Journal of Biological Innovations. 3(2):312-317. https://doi.org/ 10.46505/IJBI.2021.3210

14. Prakash, S. and Verma, A.K. (2014). Effect of Organophosphorus Pesticide (Chlorpyrifos) on the Haematology of Heteropneustes fossilis (Bloch). Int. J. of Fauna \& Biological Studies. 1(5):95-98.

15. Prakash, S. and Verma, A.K. (2020). Effect of Organophosphorus Pesticide on Biomolecules of 
fresh water fish, Heteropneustes fossilis (Bloch). Indian Journal of Biology. 7(2): 65-69.

16. Relyea, R.A. (2005). The lethal impact of roundup on aquatic and terrestrial amphibians. Ecol Appl. 15:1118-1124.

17. Sandeep Arya (2021). Freshwater Biodiversity and Conservation Challenges: A Review. International Journal of Biological Innovations. 3 (1): 74-78.

18. Scholz, .N.L., Fleishman, E., Brown, L., Werner, I., Johnson, M.L., Brooks, M.L., Mitchelmore, C.L. (2012). A perspective on modern pesticides, pelagic fi sh declines, and unknown ecological resilience in highly managed ecosystems. Bioscience. 62(4):428-434.

19. Shinde, G. S. (2021). Pesticide effect on qualitative occurrence and survival of soil bluegreen algae in laboratory condition. International Journal of Biological Innovations. 3 (1): 205-211. https://doi.org/10.46505/IJBI.2021.3122

20. Tripathi A. (2021). Eco-friendly Management of Harmful Colonization of Striped Mealybug (Ferrisia virgata) over plants by using Herbal Pesticide. International Journal of Biological Innovations. 3(1): 134-138.
21. Tripathi, P. and Tripathi, R.C. (2021). Host specificity attributes of Zygogramma bicolorata Pallister in Chitrakoot Region, India. International Journal of Biological Innovations. 3(2):306-311. https://doi.org/ 10.46505/ IJBI.2021.3209

22. Verma, A.K. (2017). Necessity of Ecological Balance for Widespread Biodiversity. Indian Journal of Biology. 4(2): 158-160.

23. Verma, A.K. (2019). Sustainable Development and Environmental Ethics. International Journal on Environmental Sciences. 10 (1): 1-5.

24. Verma, A.K. (2021). Influence of climate change on balanced ecosystem, biodiversity and sustainable development: An overview. International Journal of Biological Innovations. 3(2):331-337. https:// doi.org/10.46505/ IJBI.2021.3213

25. Verma, A.K. and Prakash, S. (2018). Haematotoxicity of phorate, an organo phosphorous pesticide on a freshwater fish, Channa punctatus (Bloch). International Journal on Agricultural Sciences, 9 (2):117-120. 